\title{
PEMANFAATAN LIMBAH BATANG PISANG KEPOK (Musa acuminata balbisiana Colla) SEBAGAI BAHAN PENYERAP ION LOGAM Zn
}

\author{
Mega Elfia ${ }^{1}$, Harni Sepryani ${ }^{2}$ \\ ${ }^{1,2}$ Akademi Analis Kesehatan Pekanbaru, Jl.Riau Ujung No.73 Pekanbaru
}

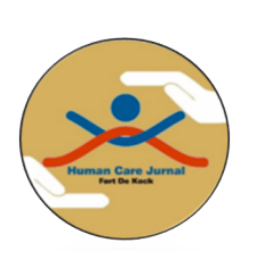

Human Care

INFO ARTIKEL:

Sejarah Artikel:

Diterima: 14-10-

2017

Disetujui: 15-10-

2017

Corresponding

Author:

mega_elfia@ya

hoo.com

Keyword:

Adsorption, Kepok

banana stem, Zinc

Tersedia online

di:

https://ojs.fdk.ac

.id/index.php/h

umancare
ABSTRAK. Teknik yang dapat digunakan untuk mengurangi tingkat pencemaran lingkungan oleh logam berat antara lain teknik adsorpsi dengan menggunakan resin sintetik penukar ion, teknik osmosis maupun penggunaan karbon aktif. Cara tersebut masih relatif mahal dan jika digunakan untuk penanganan limbah industri dalam jumlah besar. Tujuan penelitian ini adalah untuk mengeksplorasi dan mengeksploitasi limbah hasil-hasil pertanian yang berpotensi sebagai bahan penyerap ion logam berat. Pada penelitian ini dipelajari tentang penggunaan batang pisang kepok (Musa acuminata balbisiana Colla) dalam penyerapan ion logam $\mathrm{Zn}$ (II). Maka dari itu dilakukan pendekatan dengan melibatkan pengaruh $\mathrm{pH}$ larutan, konsentrasi ion logam $\mathrm{Zn}$ (II) dan ukuran partikel dari serbuk batang pisang kepok (Musa acuminata balbisiana Colla). Hasil penelitian didapatkan kondisi optimum penyerapan terhadap logam $\mathrm{Zn}$ (II). Penyerapan optimum terjadi pada $\mathrm{pH} \mathrm{3}$, konsentrasi larutan ion logam $100 \mathrm{mg} / \mathrm{L}$ dan ukuran partikel $100 \mu \mathrm{m}$. Pada kondisi optimum tersebut diperoleh kapasitas penyerapan batang pisang kepok (Musa acuminata balbisiana Colla) terhadap ion logam Zn (II) adalah $1,58 \mathrm{mg} / \mathrm{g}$. Berdasarkan hasil tersebut dapat disimpulkan bahwa batang pisang kepok (Musa acuminata balbisiana Colla) dapat digunakan sebagai bahan penyerap ion logam Zn (II).

\begin{abstract}
Technique for reduced environment pollution level becaused of heavy metals were adsorption with ion exchange synthetic resin, osmotic or used activated carbon. It was expensively techniques and if application for industry waste in large amount. The aims of this research for exploration and exploitation agriculture waste that could absorption heavy metal ions. This research was discussed about Kepok banana stem (Musa acuminate balbisiana Colla) for zinc absorption. Observation on $\mathrm{pH}$ effect, zinc consentration and particle size of it (Musa acuminate balbisiana Colla). Optimum absorption for $\mathrm{pH}$ is 3, zinc consentration is $100 \mathrm{mg} / \mathrm{L}$ and particle size is $100 \mu \mathrm{m}$. At optimum condition known absorption capacity of Kepok banana stem on zinc is 1,58 $\mathrm{mg} / \mathrm{g}$. Based on it Kepok banana stem (Musa acuminate balbisiana Colla) could be used for zinc absorbtion.
\end{abstract}

\section{PENDAHULUAN}

Pada saat ini pencemaran berlangsung di mana-mana dengan laju begitu cepat yang tidak pernah terjadi sebelumnya. Kecenderungan pencemaran akhir-akhir ini salah satunya mengarah kepada meningkatnya penggunaan bahan berbahaya beracun (B3) oleh berbagai kegiatan industri dengan pembuangan limbahnya kelingkungan (Achmad, 2004). Pencemaran perairan oleh logam berat merupakan isu lingkungan yang mendapat perhatian serius (Vasuderan et al., 2003).

$$
\text { Berbagai metoda seperti }
$$
pengendapan secara kimia, elektrodeposisi, pertukaran ion, pemisahan dengan menggunakan membran dan adsorbsi telah digunakan untuk menyerap logam berat. Adsorbsi adalah cara alternatif yang memberikan prospek yang lebih baik, karena metoda 
ini efektif untuk menyerap logam berat dengan konsentrasi yang sangat sedikit dari buangan limbah. Teknik adsorbsi dengan menggunakan resin polimer telah banyak dijual di pasaran dan digunakan dalam kimia analisis. Tetapi harganya relatif mahal. Karena itu beberapa biomaterial dari limbah hasil pertanian atau pun material biologi lain saat ini sedang diteliti secara intensif. Dan beberapa diantaranya dapat menjadi alternatif bahan penyerap (biosorpsi) yang mengurangi tingginya konsentrasi logam berat. Bahan penyerap yang terbuat dari limbah hasil pertanian ini sangat efektif dan efisien dengan biaya yang murah.

Mekanisme penyerapan logam berat oleh biometerial adalah karena pada biomaterial komposisi kandungan kimia yang umum yaitu senyawa selulosa dan lignin. Lignin merupakan senyawa polimer aromatik yang berfungsi untuk membawa air dari akar ke daun dan untuk memproteksi tanaman supaya tidak terdegradasi. Gugus fungsi yang terdapat pada lignin yaitu alkohol, aldehid, keton, karboksilat, fenol dan eter.

Penelitian tentang penyerapan logam berat telah banyak dikembangkan dalam penggunaan biomaterial belakangan ini. Beberapa tahun terakhir misalnya, penggunaan alga (Jafari et al., 2012 dan Yalcin et al., 2012), chitin dan chitosan (Prakash et al., 2011), tin (Gupta et al., 2012), Sukun (Linda et al., 2012), kembang sepatu (Vankar et al., 2011) serta kulit manggis (Zein et al., 2010) dan yang berbasiskan geomaterial seperti tanah liat (Prakash et al., 2012). Dimana biomaterial ini mudah didapat dan harganya relatif murah. Pengembangan biomaterial limbah pertanian seperti ini menjadi alternatif dalam mengatasi masalah lingkungan.

Pisang kepok (Musa acuminata balbisiana Colla) ini yang banyak dimanfaatkan adalah buah dan daun, sedangkan batangnya sangat jarang dimanfaatkan. Batang pisang kepok (Musa acuminata balbisiana Colla) merupakan limbah pertanian yang biasanya dimanfaatkan sebagai pakan ternak. Oleh karena itu, pemanfaatan batang pisang kepok (Musa acuminata balbisiana Colla) ini dijadikan sebagai biosorben untuk menyerap ion logam berat sehingga menjadikan batang pisang kepok (Musa acuminata balbisiana Colla) ini lebih bermanfaat. Ketersediaan bahan baku batang pisang kepok (Musa acuminata balbisiana Colla) banyak ditemukan dengan mudah dan murah. Menurut penelitian yang dilakukan oleh Suarsa dkk., (2012) tentang uji fitokimia batang pisang kepok (Musa acuminata balbisiana Colla), dengan hasil bahwa adanya senyawa aktif berupa flavonoid dan tanin.

Berdasarkan uraian diatas maka dalam penelitian ini dipelajari tentang penggunaan batang pisang kepok (Musa acuminata balbisiana Colla) dalam penyerapan ion logam $\mathrm{Zn}(\mathrm{II})$. Maka dari itu dilakukan pendekatan dengan melibatkan pengaruh variasi $\mathrm{pH}$ larutan, konsentrasi ion logam dan ukuran partikel serbuk batang pisang kepok (Musa acuminata balbisiana Colla). Pengukuran ion logam menggunakan Spektroskopi Serapan Atom (Atomic Absorption Spectrometer / AAS).

\section{METODE PENELITIAN}

Kegiatan ini dilakukan dalam dua tahap kerja. Tahap pertama persiapan yaitu pembuatan biosorben dari limbah 
batang pisang kepok (Musa acuminata balbisiana Colla). Tahap kedua yaitu perlakuan biosorben terhadap larutan ion logam Zn (II) dan dianalisis secara Spektrofotometri Serapan Atom (SSA) pada variasi $\mathrm{pH}$ larutan ion, konsentrasi ion logam dan ukuran partikel biosorben.

\section{Instrumen Pelaksanaan}

Alat-alat yang digunakan dalam penelitian ini adalah neraca digital KERN 220-4M Germany, pH Universal Merck, blender, kertas saring whatman, dan peralatan gelas lain sesuai prosedur kerja.

Bahan-bahan yang digunakan adalah limbah batang pisang kepok (Musa acuminata balbisiana Colla) diambil di jalan Cipta Karya, Gang Limbat, Pekanbaru, Riau. Reagen yang digunakan untuk penelitian ini adalah $\mathrm{ZnCl}_{2}, \mathrm{HNO}_{3} 65 \%$, $\mathrm{NaOH}$ yang semuanya mempunyai tingkat kemurnian yang tinggi keluaran E-Merck Darmstad, Germany, etanol destilasi dan akuades.

Pembuatan biosorben batang pisang kepok (Musa acuminata balbisiana Colla)

Limbah batang pisang kepok (Musa acuminata balbisiana Colla), dibersihkan dari batuan dan tanah yang menempel, kemudian dicuci dengan air bersih dan dijemur di udara terbuka. Setelah kering kemudian dihaluskan dan diayak dengan ayakan berdasarkan ukuran partikel yang akan dipakai $(100 \mu \mathrm{m}, 120 \mu \mathrm{m}, 170 \mu \mathrm{m})$. Limbah batang pisang kepok (Musa acuminata balbisiana Colla) dengan ukuran tersebut direndam dalam larutan $\mathrm{HNO}_{3}$ 0,1M selama 2 jam sambil sesekali diaduk. Hasil rendaman disaring kemudian dicuci dengan akuades. Setelah itu direndam dengan etanol selama 2 jam, kemudian dikeringkan kembali.

Penentuan kondisi optimum limbah batang pisang kepok (Musa acuminata balbisiana Colla)

Pada penelitian ini dilakukan dengan cara dinamis (menggunakan kolom), untuk mengetahui kemampuan penyerapan ion logam Zn (II) oleh batang pisang kepok Musa acuminata balbisiana Colla. Beberapa variabel yang akan dipelajari adalah $\mathrm{pH}$ ion logam, konsentrasi ion logam dan ukuran partikel biosorben.

\section{Pengaruh $\mathrm{pH}$ ion logam}

Biosorben dengan ukuran partikel 100 $\mu \mathrm{m}$ sebanyak 1 gram dimasukkan ke dalam kolom dan dielusi dengan $20 \mathrm{~mL}$ larutan ion logam konsentrasi $50 \mathrm{mg} / \mathrm{L}$ dengan $\mathrm{pH}$ larutan ion logam yang divariasikan 2, 3, 4, 5, 6 dan 8 dengan kecepatan alir larutan ion logam yaitu 2 $\mathrm{mL} /$ menit. Filtrat yang dihasilkan dianalisis dengan Spektrofotometer Serapan Atom. Berdasarkan perlakuan ini diperoleh $\mathrm{pH}$ ion logam optimum.

\section{Pengaruh konsentrasi larutan terhadap penyerapan ion logam}

Biosorben ditimbang 1 gram dengan ukuran partikel $100 \mu \mathrm{m}$, kemudian dimasukan kedalam kolom, dan dielusi dengan $20 \mathrm{~mL}$ larutan ion logam konsentrasi yang divariasikan 5, 10, 25, 50, 75, dan $100 \mathrm{mg} / \mathrm{L}$ dengan $\mathrm{pH}$ optimum pada kecepatan alir 2 $\mathrm{mL} /$ menit. Filtrat yang dihasilkan dianalisis dengan Spektrofotometer Serapan Atom. Perlakuan ini akan diperoleh konsentrasi ion logam optimum. 


\section{Pengaruh ukuran partikel biosorben} Biosorben ditimbang 1 gram dengan ukuran partikel $100 \mu \mathrm{m}$, kemudian dimasukan ke dalam kolom, dan dielusi dengan $20 \mathrm{~mL}$ larutan ion logam konsentrasi optimum dengan kecepatan alir $2 \mathrm{~mL} /$ menit pada $\mathrm{pH}$ optimum. Filtrat yang dihasilkan dianalisis dengan Spektrofotometer Serapan Atom. Hal ini juga dilakukan pada ukuran partikel $170 \mu \mathrm{m}$, dan $200 \mu \mathrm{m}$, sehingga diperoleh ukuran partikel absorben optimum.

\subsection{Analisis Data}

Data yang diperoleh dari hasil penelitian akan disajikan dalam bentuk tabel, grafik, dan gambar. Kapasitas serapan ion logam oleh limbah batang pisang kepok (Musa acuminata balbisiana Colla) dihitung dengan menggunakan persamaan isoterm Langmuir dengan nilai:

$$
\mathrm{Q}=\frac{C i-C f}{m} \times V
$$

Dimana:

$\mathrm{Q}=$ kapasitas penyerapan $(\mathrm{mg}$ ion logam/g biomaterial

$\mathrm{Ci}=$ konsentrasi awal ion logam $(\mathrm{mg} / \mathrm{L})$

$\mathrm{Cf}=$ konsentrasi akhir $(\mathrm{mg} / \mathrm{L})$

$\mathrm{V}=$ volume ion logam $/$ larutan

$\mathrm{m}=$ massa biosorben / biomaterial $(\mathrm{g})$

\section{HASIL DAN PEMBAHASAN}

Pengaruh $\mathrm{pH}$ Larutan terhadap Kapasitas Penyerapan Ion Logam

Pengaruh dari $\mathrm{pH}$ terhadap daya serap batang pisang kepok (Musa acuminata balbisiana Colla) pada larutan ion logam $\mathrm{Zn}$ (II) dengan variasi $\mathrm{pH}$ dari 2 - 8 dengan laju alir $2 \mathrm{ml} /$ menit. $\mathrm{pH}$ merupakan parameter yang sangat penting dalam proses biosorpsi karena $\mathrm{pH}$ mempengaruhi gugus-gugus fungsi yang terdapat pada biomaterial untuk penyerapan dan kompetisi ion logam supaya teradsorpsi pada gugus aktif (Jafari et al., 2012).

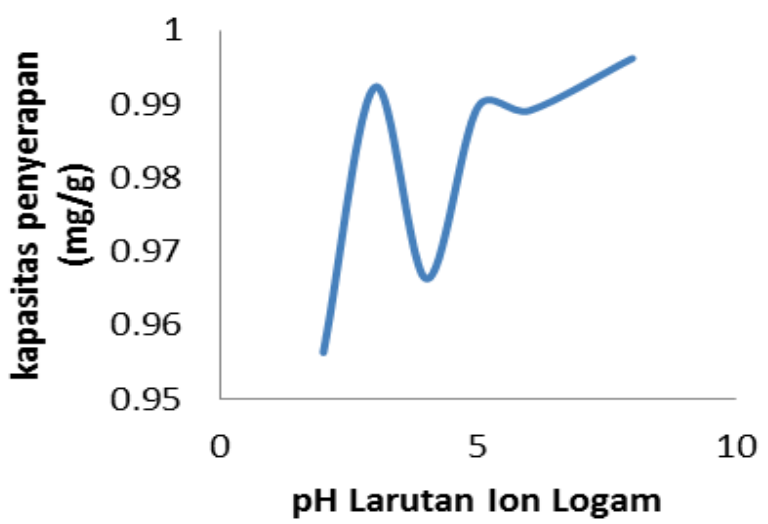

Gambar 1. Pengaruh pH Larutan Ion Zn terhadap kapasitas penyerapan limbah batang pisang kepok (Musa acuminata balbisiana Colla)

Gambar 1. diketahui bahwa $\mathrm{pH}$ optimum untuk logam Zn(II) yaitu pada $\mathrm{pH}$ 3, dengan kapasitas penyerapan masing-masing $0.992 \mathrm{mg} / \mathrm{g}$. Hasil yang hampir sama untuk pengaruh $\mathrm{pH}$ juga dilaporkan oleh para peneliti lain (Yalcin et al., 2012 dan Prakash et al., 2011) dimana pengaruh $\mathrm{pH}$ untuk logam kation pada range 3-6.

Pada $\mathrm{pH}$ rendah peyerapan ion logam rendah dapat dikaitkan pada kompetisi yang terjadi antara kation logam dengan $\mathrm{H}^{+}$untuk teradsorbsi pada sisi aktif batang pisang kepok Musa acuminata balbisiana Colla.batang pisang kepok Musa acuminata balbisiana Colla mengandung senyawa flavonoid dan tanin. Pada $\mathrm{pH}$ rendah, gugus fungsi terprotonasi dan membatasi penyerapan logam karena terjadi kompetisi dengan $\mathrm{H}^{+}$. Seiring dengan peningkatan $\mathrm{pH}$, gugus fungsi seperti amino, fosfat, dan gugus karboksil akan terbuka dan membawa muatan negatif sehingga ion 
logam akan teradsorpsi (Prakas et al., 2011).

\section{Pengaruh Konsentrasi Ion Logam}

Pengaruh konsentrasi ion logam $\mathrm{Zn}$ (II) dalam larutan dilakukan dengan konsentrasi 5, 10, 25, 50, 75, dan 100 $\mathrm{mg} / \mathrm{L}$. Konsentrasi ion logam berhubungan dengan banyaknya ion logam yang dapat berinteraksi dengan sisi aktif material penyerap. Tetapi pada saat tertentu jumlah sisi aktif sama dengan jumlah ion logam, pada saat tersebut penyerapan yang terjadi akan konstan sehingga kapasitas penyerapan akan menurun dengan meningkatnya konsentrasi (Ramadhan dan Handajani, 2007). Hasil pengukuran pengaruh konsentrasi ion logam dapat dilihat pada gambar 2.

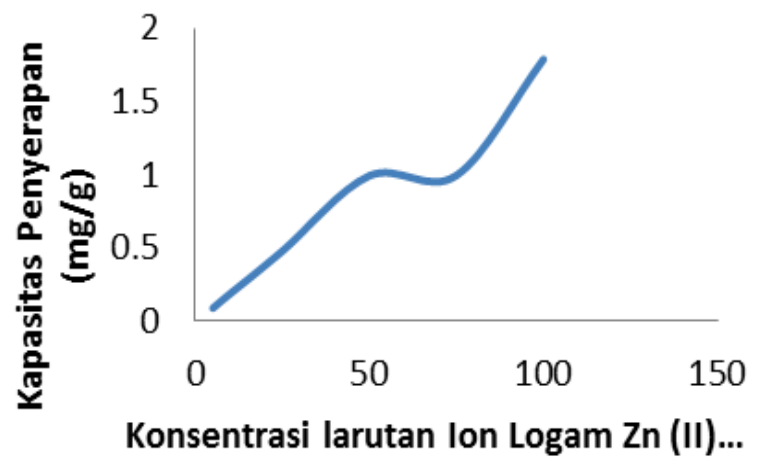

Gambar 2. Pengaruh konsentrasi larutan ion logam Zn(II) terhadap kapasitas penyerapan serbuk batang pisang kepok (Musa acuminata balbisiana Colla)

Adsorpsi maksimum ion logam Zn(II) pada konsentrasi $100 \mathrm{mg} / \mathrm{L}$, bisa dilihat kapasitas penyerapan masih mengalami peningkatan ini berati gugus aktifnya masih mampu menerima ion logam sampai nanti pada titik jenuh. Kapasitas penyerapan ion logam Zn (II) terhadap serbuk batang pisang kepok
(Musa acuminata balbisiana Colla) adalah $1,788 \mathrm{~g} / \mathrm{mg}$.

Pengaruh Ukuran Partikel terhadap Kapasitas Penyerapan Ion Logam

Kapasitas penyerapan ion logam Zn(II) dipengaruhi oleh ukuran partikel, dimana hal ini berhubungan dengan luas permukaan. Semakin kecil ukuran partikel, akan semakin besar luas permukaan dan semakin banyak interaksi pada permukaan partikel dengan gugus fungsi hidroksil, amino, ester, karboksil dan eter, mengakibatkan kapasitas penyerapan meningkat.

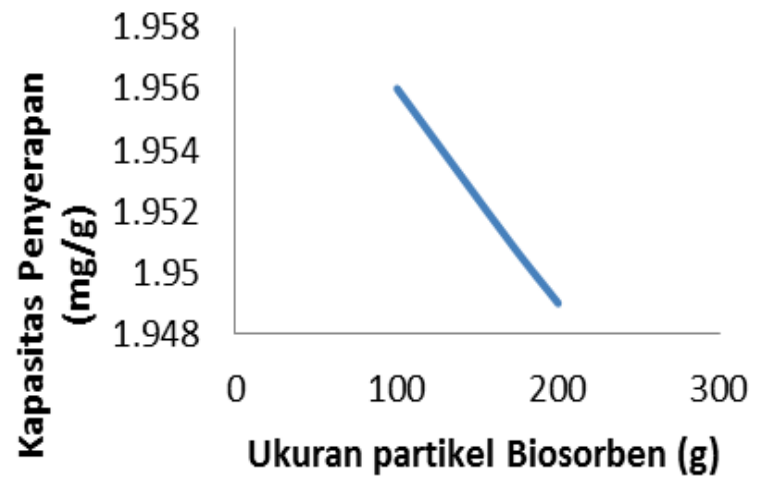

Gambar 3. Pengaruh Ukuran partikel Biosorben terhadap kapasitas penyerapan serbuk batang pisang kepok (Musa acuminata balbisiana Colla) terhadap ion loga Zn (II)

$\begin{array}{ccr}\text { Diamati } & \text { bahwa } & \text { kapasitas } \\ \text { penyerapan } & \text { meningkat } & \text { dengan }\end{array}$ penurunan ukuran partikel biosorben. Peristiwa adsorpsi adalah fenomena permukaan, sehingga tingkat penyerapan berhubungan erat dengan luas permukaan. Oleh karena itu, semakin kecil ukuran partikel, semakin besar penyerapan yang akan terjadi, karena ion-ion akan menembus ke pori-pori dalam partikel.(Alothman et al., 2012); (Vankar et al., 2011). Untuk logam Zn(II) ukuran partikel optimum yaitu pada 100 
$\mu \mathrm{m}$. Dimana kapasitas penyerapan optimum pada ukuran partikel terkecil. Israel dan Eduok (2012) juga melaporkan bahwa kapasitas penyerapan optimum untuk logam $\mathrm{Zn}$ terjadi pada ukuran partikel $\leq 180 \mu \mathrm{m}$. Dari hasil yang didapat kapasitas penyerapan optimum batang pisang pisang kepok (Musa acuminata balbisiana Colla) adalah 1,956 g/mg.

\section{KESIMPULAN}

Dari hasil penelitian yang telah dilakukan terhadap penyerapan ion logam Zn(II) oleh batang pisang kepok (Musa acuminata balbisiana Colla) didapat hasil Kapasitas penyerapan maksimum untuk logam $\mathrm{Zn}$ (II) terjadi pada $\mathrm{pH} 3$ dengan kapasitas penyerapan 0,992 $\mathrm{mg} / \mathrm{g}$. Konsentrasi optimum untuk ion logam Zn(II) adalah $100 \mathrm{mg} / \mathrm{L}$ dengan kapasitas penyerapannya adalah 1,788 $\mathrm{mg} / \mathrm{g}$. .Ukuran partikel untuk ion logam Zn (II) kapasitas penyerapan optimum terjadi pada ukuran partikel $100 \mu \mathrm{m}$ dengan kapasitas penyerapan sebesar 1,956 mg/g. Jadi dapat disimpulkan bahwa serbuk batang pisang kepok (Musa acuminata balbisiana Colla) dapat digunakan sebagai biosorben untuk penyerap ion logam Zn (II).

\section{UCAPAN TERIMAKASIH}

Penulis mengucapkan terima kasih kepada pihak DRPM Ditjen Penguatan Risbang, Kementrian Riset, Teknologi, Dan Pendidikan Tinggi. yang telah memberikan dana untuk riset ini

\section{REFERENSI}

Achmad, Rukaesih. 2004. Kimia Lingkungan. ANDI Yogyakarta, Yogyakarta
Al Othman Z. A., M. Naushad, R. Ali. 2012. Kinetic, equilibrium isotherm and thermodynamic studies of $\mathrm{Cr}(\mathrm{VI})$ adsorption onto low-cost adsorbent developed from peanut shell activated with phosphoric acid. Environ Sci Pollut Res. DOI 10.1007/s11356-012-1259-4

Gupta V. K., D. Pathania, S. Agarwal, S. Sharma. 2012. Removal of Cr(VI) onto Ficus carica biosorbent from water. Environ Sci Pollut Res. DOI 10.1007/s11356-012-1176-6

Israel, U and Eduok, U. M. 2012. Biosorption of zinc from aqueous solution using coconut (Cocos nucifera L) coir dust. Scholars Research Library. 4 (2):809-819.

Jafari N., Z. Senobari. 2012. Removal of $\mathrm{Pb}$ (II) ion from aqueous solution by Cladophora rivularis (Linnaeus) hoek. The Scientific World Journal, vol. 2012

Linda B., L. Lim, N. Priyantha, D. T. B. Tennakoon, M. K. Dahri. 2012. Biosorption of cadmium(II) and copper(II) ions from aqueous solution by core of Artocarpus odoratissimus. Environ Sci Pollut Res. 19:3250-3256

Prakash N., P. N. Sudha., N. G. Renganathan. 2011. Copper and cadmium removal from synthetic industrial wastewater using chitosan and nylon 6. Environ Sci Pollut Res. 19: 2930-2941. 
Prakash N., S. Latha., P. N. Sudha., N. G. Renganathan. 2012. Influence of clay on the adsorption of heavy metals like copper and cadmium on chitosan. Environ Sci Pollut Res.

Ramadhan, B dan Hanjani, M. 2007. Biosorpsi logam berat $\mathrm{Cr}$ (VI) dengan menggunakan biomass Saccharomyces cerevisiae. ITB. Bandung.

Vankar P. S., R. Sarswat, R. Sahu. 2012. Biosorption of Zinc Ions from Aqueous Solutions onto Natural Dye Waste of Hibiscus rosa sinensis: Thermodynamic and Kinetic Studies. Environmental Progress \& Sustainable Energy. 31, No.1

Vasuderan P., V. Padmavathy, S.C. Dhingra. 2003. Kinetics of biosorption of cadmium on Baker's yeast. Bioresour. Technol. 89 (3): 281-287.
Yalcin S., S. Sezer., R. Apak. 2012. Characterization and lead(II), cadmium(II), nikel(II) biosorption of dried marine brown macro algae Cytoseria barbata. Environ Sci Pollut Res. 19: 3118-3125.

Zein. R., R. Suhaili, F. Earnestly, Indrawati, E. Munaf. 2010. Removal of $\mathrm{Pb}(\mathrm{II}), \mathrm{Cd}(\mathrm{II})$ and from aqueous solution using Garcinia mangostana L. fruit shell. Journal of Hazardous Materials. 181: 52-56. 